Izabela Olejnik

Biblioteka Politechniki Łódzkiej

Uniwersytet Wrocławski

\title{
Miejsce i funkcja biblioteki żydowskiej w XXI w. na przykładzie Biblioteki Medem w Paryżu
}

\section{Wstęp}

Istniejąca od 1929 r. Biblioteka Medem stanowi ważny punkt na mapie żydowskiego Paryża. Jej historia odzwierciedla losy społeczności żydowskiej na przestrzeni ostatnich osiemdziesięciu lat. Księgozbiór biblioteki nawiązuje do zagłady narodu oraz stanowi próbę ocalenia samego języka żydowskiego, którym do wybuchu II wojny światowej posługiwało się 10-12 milionów Żydów na całym świecie ${ }^{1}$.

\section{Lata 1925-1940 - powstanie i rozwój biblioteki}

Pierwsze próby założenia biblioteki żydowskiej w Paryżu wiążą się z napływem żydowskich emigrantów z Europy Wschodniej, którego szczyt nastąpił w czasie I wojny światowej. Od samego początku biblioteka była związana z działalnością partii socjalistycznej Bund ${ }^{2}$ we Francji. W gronie emigrantów znaleźli się przedstawiciele różnych ugrupowań politycznych jak również ludzie pióra. Zanim utworzono w 1929 r. Bibliotekę im. Vladimira Medema doszło do kilku istotnych wydarzeń oraz powołania kilku efemerycznych bibliotek. Pierwszą z nich była niewielka biblioteka przy ArbeterFarejn Kemfer utworzona w 1904 roku. Przy bibliotece działał teatr z siedzibą przy 27, Rue des Ecouffes, w sercu dzielnicy żydowskiej Marais. Niespełna 20 lat później, w 1922 r., staraniem bundowców, komunistów oraz

\footnotetext{
${ }^{1}$ Beer H.: Yiddish without Yiddish. „European Judaism” 2009, vol. 42, nr 2, s. 11.

2 Bund właśc. Ogólnożydowski Związek Robotniczy „Bund” na Litwie, w Polsce i w Rosji - najsilniejsza i najliczniejsza żydowska partia robotnicza w Polsce w okresie międzywojennym, utworzona w Wilnie w październiku 1897. Konsekwentnie przeciwstawiała się programowi syjonistycznemu i opowiadała się za rozwiązaniem kwestii żydowskiej w Polsce w drodze socjalistycznej przemiany ustrojowej i autonomii kulturalno-narodowej Żydów. Zob. Polski słownik judaistyczny: dzieje, kultura, religia, ludzie. T.1. Oprac. Z. Borzymińska., R. Żebrowski. Warszawa: Prószyński i S-ka, 2003, s. 243-244.
} 
członów Poalej-Syjon lewicy utworzono Ligę Kultury ${ }^{3}$, której jedną z głównych instytucji była biblioteka. Trzy lata później komuniści przejęli władzę w strukturach Kultury Ligi, a w konsekwencji przejęli także pieczę nad biblioteką. Wobec takiego przebiegu wydarzeń, działacze Bundu wystąpili z projektem utworzenia własnej organizacji, która zajmowałby się promowaniem kultury jidysz. Nazwali ją Arbeter-klub ojfn nomen Vladimir Medem ${ }^{4}$, na cześć czołowego ideologa partii ${ }^{5}$.

W 1928 r. powstała Biblioteka Nomberga przy Związku Medem. Jak pisze Gilles Rozier, dyrektor Maison de la Culture Yiddish-Bibliothèque Medem, wśród jej założycieli było ośmiu emigrantów: Icchok Blumenstein, Meir Mendelson, Chaim Golub, Lejb Tabacznik, Avrom Zusman, Eli Szwiriński, Dovid Lejber oraz Kiwa Wajsbrot ${ }^{6}$. By zdobyć niezbędne fundusze na zakup książek zorganizowano wieczór literacki z udziałem takich pisarzy jak: Szolem Asz, Dawid Einhorn, Zalmen Szneur czy Perec Hirszbejn. Za zebrane pieniądze zakupiono meble oraz pierwsze egzemplarze książek. Dodatkowo zbiory biblioteki powiększyły dary Szolema Asza, który ofiarował 200 książek i Barucha Vladecka z Nowego Jorku, który przekazał na rzecz biblio-

${ }^{3}$ Kultur-Liga właśc. Liga Kultury Proletariackiej; nazwana też Ligą Kultury Żydowskiej - organizacja kulturalno-oświatowa (gł. jidyszystyczna), w której dominowały zwłaszcza początkowo wpływy polityczne Bundu. Została założona w Kijowie w 1917, jednak pod władzą sowiecką mogła jeszcze tylko przez pewien czas rozwijać aktywną działalność (w tym wydawnicza). Jej celem był „rozwój i szerzenie żydowskiej kultury wszelkich gałęzi ludzkiej twórczości, jak literatura, sztuka, muzyka, teatr itp. oraz pomoc $\mathrm{w}$ budowaniu wszelkiego rodzaju instytucji kulturalnooświatowych".[...] W okresie międzywojennym Kultur Liga stała się jedną z ważniejszych oficyn wydawniczych, publikujących książki w jidysz o bardzo różnorodnej formie i treści. Zob. Polski stownik judaistyczny..., s. 845-846.

${ }^{4}$ Robotniczy Klub im. Vladimira Medem.

${ }^{5}$ Włodzimierz Medem (1879-1923) czołowy przywódca Bundu, redaktor wielu czasopism socjalistycznych. Był synem zasymilowanego lekarza, oficera rosyjskiego, który ochrzcił syna w obrządku prawosławnym. Dopiero kontakty z kolegami w mińskim gimnazjum zainicjowały proces powrotu Medema do żydowskiej autoidentyfikacji. Studiował prawo na uniwersytecie w Kijowie. W tym czasie został zwolennikiem marksizmu. Za udział w organizowaniu strajku studenckiego (1899) został z uczelni wydalony i był więziony. Po powrocie do Mińska ostatecznie związał się z Bundem. Był jednym z pierwszych, którzy zaczęli głosić potrzebę włączenia się Bundu w walkę o gminy żydowskie, w rozwój kultury jidysz (w tym szkolnictwa), w walkę o prawo do świętowania soboty. W czasie I wojny światowej znalazł się w Warszawie i stal się czołowym ideologiem Bundu; zaczął posługiwać się j. jidysz. Zob. Polski stownik judaistyczny: dzieje, kultura, religia, ludzie. T.2. Warszawa: Prószyński i S-ka, 2003, s. 243-244.

${ }^{6}$ Rozier G.: The Bibliotheque Medem: eighty years serving Yiddish culture. „Judaica Librarianship" 2009, vol. 15, s. 26. 
teki 300 książek $^{7}$. W 1932 r. Związek Medem po raz kolejny zmienił swoją siedzibę, lokując swoje zbiory przy 111, Rue Vieille-du-Temple (w trzeciej dzielnicy) ${ }^{8}$. Pod tym adresem biblioteka miała do swojej dyspozycji przestronne pomieszczenia, z których większe służyło jako czytelnia, zaś funkcję magazynów pełniły szafy ulokowane w innym pomieszczeniu. W kolejnych latach księgozbiór biblioteki został rozbudowany o książki sprowadzane z Polski oraz ze Stanów Zjednoczonych. Do biblioteki trafiły również zbiory ze zlikwidowanej Biblioteki Związku Hat Makers w liczbie 800 woluminów.

Biblioteka, w której gromadzono książki i prasę żydowską pisaną w języku jidysz, stała się miejscem licznych imprez kulturalnych oraz spotkań żydowskich emigrantów. Tuż przed wybuchem II wojny światowej jej zbiory wynosiły 3,3 tys. wol., zaś liczba czytelników dochodziła do $185^{9}$.

\section{Lata 1940-1944 - okupacja hitlerowska}

Lata okupacji hitlerowskiej stanowią najsmutniejszy i najbardziej dramatyczny okres w dziejach biblioteki. W październiku 1940 r. w wyniku ogłoszonego przez rząd Vichy „Statutu żydowskiego” 30 tys. Żydów zostało pozbawionych wolności. Wcześniej przed deportacją „ludność żydowska została ogołocona $\mathrm{z}$ majątku, wyrzucona $\mathrm{z}$ zajmowanych stanowisk publicznych, ograniczona w prawach publicznych i zmuszona do noszenia specjalnych znaków hańby"10. Deportacje do obozu zagłady Auschwitz rozpoczęły się w marcu 1942 r. Punktem zbiorczym był obóz w Drancy. W pierwszej kolejności do obozu kierowano emigrantów z Europy Wschodniej, jednak po kilku miesiącach zaczęto deportować również obywateli podbitych państw zachodnioeuropejskich.

Jesienią 1942 r. funkcjonariusze gestapo złożyli wizytę w siedzibie Bundu, w której przez cały okres okupacji prowadzono bezpłatną stołówkę. Żywność przechowywano w bibliotece, w szafkach, które rozmiarem były

\footnotetext{
${ }^{7}$ Tamże, s. 26.

${ }^{8} \mathrm{~W}$ tym samym roku przy Bibliotece utworzono organizację Arbeter-Ring, która rozwijała się razem ze swoją macierzystą instytucją. Służyła robotnikom, organizowano w niej dodatkowe zajęcia.

${ }^{9}$ Biblioteka Nomberga była jedną z sześciu bibliotek żydowskich, które w tym czasie działały w Paryżu. Były to m.in.: Biblioteka im. Jefim Pernikowa (największa spośród nich wszystkich, jej zbiory zarówno w języku hebrajskim oraz jidysz wynosiły ogółem 6200 wol.), Żydowska Biblioteka Ludowa im. Szolema Alejchema (zbiory liczyły 3800 wol.), Bibliothèque Kouliche - była z kolei prywatną biblioteką założoną z inicjatywy filantropa. Rozier G.: dz. cyt., s. 27.

${ }^{10}$ Tych F. (red.): Pamięć: historia Żydów polskich przed, w czasie, i po Zagładzie. Warszawa: Gołda Tencer : Fundacja Shalom, 2004, s. 153.
} 
zbliżone do półek z książkami. Podczas wizyty gestapo szafki blokowały dostęp do księgozbioru, który znajdował się tuż za nimi. Gestapo zamierzało wrócić z zamiarem zarekwirowania przechowywanej żywności. W obliczu niebezpieczeństwa „,członkowie Bundu, którzy pozostali w Paryżu przenieśli książki do piwnicy"11. Ponad 3 tys. książek, które ukryto w piwnicy w szczelnie zabezpieczonych i zamkniętych pudłach, uniknęło zniszczenia.

Biblioteka Nomberga wznowiła działalność 14 października 1944 r. kilka tygodni po wyzwoleniu Paryża. Spośród ośmiu założycieli biblioteki wojnę przeżyło tylko dwóch: Lejb Tabacznik i Eli Szwiriński. Przestał istnieć Związek Medem, ale w dalszym ciagu funkcjonowało Arbeter-Ring. W wyniku zabiegów niektórych bundowców nazwę biblioteki zmieniono na Bibliotekę Medem przy organizacji Arbeter Ring.

\section{Lata 1945-1970 - okres powojenny}

Odrodzenie społeczności żydowskiej po zakończeniu działań wojennych nie było łatwym i prostym procesem. Przede wszystkim liczba członków gminy żydowskiej drastycznie zmalała. Według szacunków Davida Weinberga "z około 80 tys. Żydów, którzy zostali deportowani z Francji w czasie wojny, zaledwie 3,5 tys. powróciło do swoich domów. Przedwojenna żydowska społeczność Paryża, niegdyś tak dynamiczna, uległa osłabieniu wskutek utraty ok. 70 tys. swoich członków"12. Borykano się z licznymi problemami. Przede wszystkim Żydzi powracający z obozów oraz wychodzący z ukrycia wymagali natychmiastowej pomocy, w szczególności medycznej i społecznej. Jednak najpierw musieli zmierzyć się z wrogością i niechęcią lokalnych mieszkańców. Co więcej, rząd Francji nie był zainteresowany zapewnieniem jakiejkolwiek pomocy Żydom. Wspomniane problemy pogłębiała dodatkowo walka o odzyskiwanie dzieci żydowskich wychowywanych w domach chrześcijańskich, a także restytucja mienia żydowskiego, która niekiedy przechodziła w wieloletnie batalie" ${ }^{\text {"13 }}$. Niezmiernie ważnym wydarzeniem dla omawianego okresu było powstanie państwa Izrael w 1948 r., co pozwoliło Żydom zamieszkującym w Paryżu na dokonanie wyboru miejsca zamieszkania. Wielu Żydów z tej możliwości skorzystało.

${ }^{11}$ Rozier G.: dz. cyt., s. 28.

12 Weinberg D.: The reconstruction of the French Jewish community after world war II. [W:] She'erit hapletah, 1944-1948: rehabilitation and political struggle: proceedings of the sixth Yad Vashem International Historical Conference. Jerusalem: Yad Vashem, 1985, s. 168.

${ }^{13}$ Szuchta R., Trojański P.: Holocaust: zrozumieć dlaczego. Warszawa: Mówią wieki : Bellona, 2006, s. 268. 


\section{Il. 1. Karta czytelnika, pisarza, Chaima Gradego.}

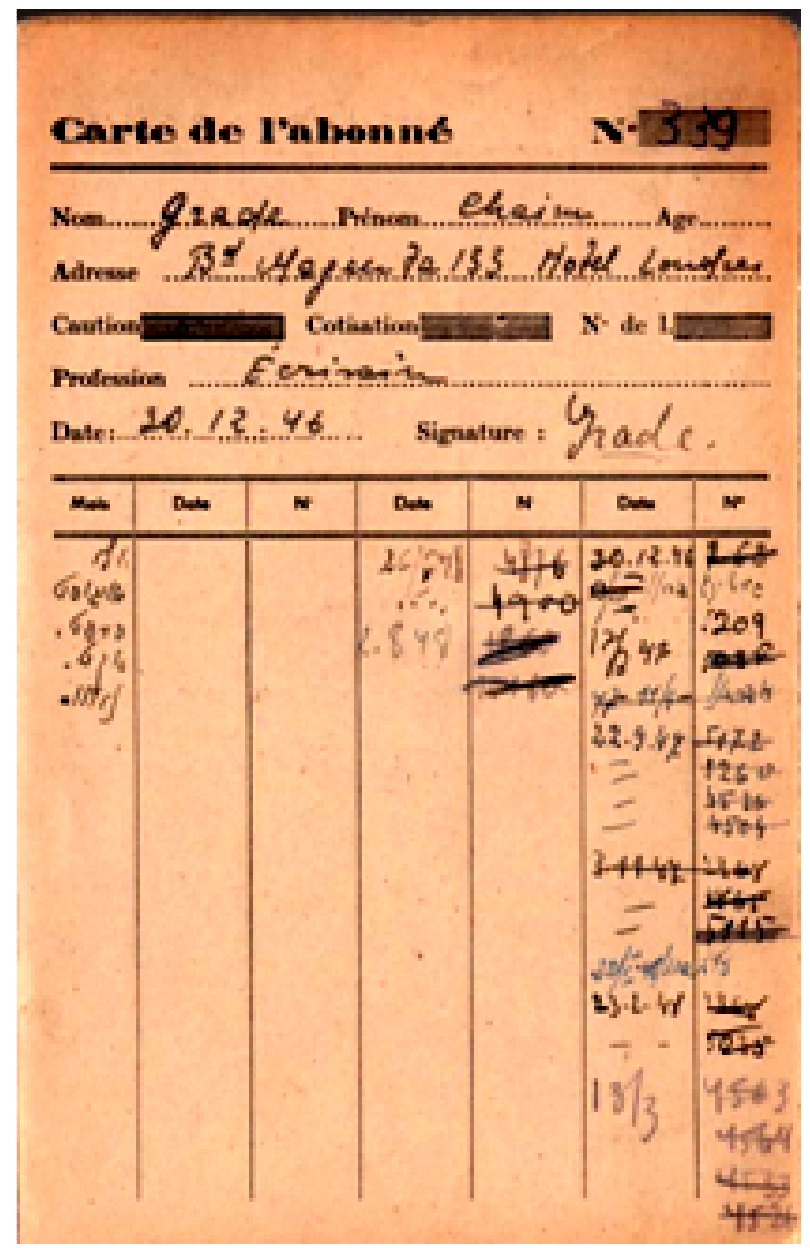

Źródło: http://yiddishweb.com/Locaux/Locauxeng.html.

Pomimo atmosfery niechęci i wrogości, stopniowo dążono do odbudowy życia kulturalnego. Zdaniem Icchoka Niborskiego, którego wkład w rozwój języka jidysz jest nieoceniony, stało się to możliwe „dzięki częściowemu napływowi ocalałych z Polski i Litwy, wśród, których liczni byli intelektualiści i pisarze jidysz"14. Efektem ich działań było wzbogacenie kultury jidysz, czego najlepszym wyrazem było wydawanie trzech tytułów codziennych gazet w języku jidysz, uruchomienie pięciu bibliotek w samym Paryżu, wzrost pu-

${ }^{14}$ Niborski I.: Yiddish culture in France and in the French-speaking areas. „European Judaism” 2009, vol. 42, nr 2, s. 4. 
blikacji w czasopismach poświęconych takim zagadnieniom jak zdrowie czy dzieci, a także wydawanie kilku czasopism literackich. Regularnie publikowano prozę, zbiory poezji, przyznawano nagrody literackie, nie bez znaczenia była także działalność teatralna.

Mimo ożywienia kultury jidysz dostrzeżono jeszcze jeden problem, który miał decydujące znaczenie dla przyszłości - kwestię przekazania tej kultury młodszemu pokoleniu. Asymilacja językowa, słaba edukacja w szkołach skutkowały nie tylko spadkiem czytelnictwa, ale co najistotniejsze malejącą liczbą osób posługujących się jidysz.

\section{W obliczu nadchodzących zmian}

Od lat 70. XX w. dotychczasowi przedwojenni użytkownicy, aktywiści i propagatorzy języka jidysz stopniowo odchodzili z przestrzeni publicznej. Istniała obawa, że razem z nimi zaniknie wielowiekowa kultura, literatura, dziedzictwo kulturowe. By temu zapobiec badacze, naukowcy, pasjonaci podjęli szereg inicjatyw mających na celu ochronę i promowanie kultury żydowskiej. Do najważniejszy działań można zaliczyć:

- włącznie nauczania jidysz do programu akademickiego w kilku miastach Francji, w tym Paryżu,

- żydowskie organizacje jak Arbeter Ring w dalszym ciagu organizowały liczne kursy dla dorosłych,

- wykształcenie nowego grona specjalistów i tłumaczy jidysz, którzy zaangażowali się w działalność translatorską, przybliżając społeczności francuskojęzycznej bogactwo i piękno literatury żydowskiej,

- wydawanie od 1997 r. miesięcznika ,Jidisze Heftn”, który zastąpił zlikwidowane codzienne gazety żydowskie,

- utworzenie w 1981 r. Association pour l'Étude et la Diffusion de la Culture Yiddish (AEDCY), jedynej tego typu pro-jidyszowej placówki w Europie ${ }^{15}$.

Biblioteka Medem przez cały okres powojenny funkcjonowała, powiększając swój księgozbiór. Oprócz książek w języku jidysz biblioteka zaczęła gromadzić również książki w języku francuskim dotyczące szeroko pojmowanej tematyki żydowskiej. Rozszerzyło się także grono czytelników. Do tej pory jedynymi czytelnikami biblioteki były osoby żydowskojęzyczne, które poznały jidysz $\mathrm{w}$ rodzinnym domu. Teraz z biblioteki zaczęli korzystać studenci, badacze, thumacze, pasjonaci realizujący konkretne zainteresowania naukowe, osoby, które po latach w różnych okolicznościach odkryły swoje żydowskie pochodzenie i zapragnęły pozwać swoją kulturę. Aktywna działal-

\footnotetext{
${ }^{15}$ Niborski I.: dz. cyt., s. 5.
} 
ność biblioteki, a w szczególności jej bogaty księgozbiór zaspokajał różnorodne potrzeby czytelnicze i naukowe ${ }^{16}$. Zmieniająca się grupa odbiorców spowodowała automatyczną zmianę statusu biblioteki, podnosząc ją do rangi biblioteki naukowej.

W 1979 r. kierownik biblioteki Kiwa Wajsbrot zdecydował o zmianie prawnej statutu biblioteki i przekształceniu jej w stowarzyszenie non-profit, dzięki czemu biblioteka mogła odłączyć się od Arbeter Ring i stać się samodzielną instytucją. Dało to także możliwość ubiegania się o fundusze na rozbudowę księgozbioru i modernizację biblioteki. W tym samym roku, Ichcok Niborski rozpoczął pracę nad tworzeniem katalogu kartkowego alfabetycznego i tematycznego.

W latach 90. XX w. biblioteka Medem przejęła zbiory ze zlikwidowanych bibliotek:

- 6 tys. wol. w języku jidysz z organizacji komunistycznej Union des Juifs pour la Resistance et l'Entraide (UJRE), która uległa likwidacji ze względu na brak czytelników (1993),

- 3 tys. wol. z biblioteki Kouliche (1993),

- 6 tys. wol. jidysz z biblioteki Fédération des Sociétés de France (1997),

- 2 tys. wol. dotyczących syjonizmu z biblioteki należącej do Foyer Ouvrier Juif (1997),

- 1 tys. rzadkich książek z prywatnej kolekcji należącej do Betsalela Frankla, bibliotekarza, kolekcjonera i sprzedawcy książek jidysz w Jaffie, w tym unikatową kolekcję literatury brukowej z 2 poł. XIX w. licząca 200 tytułów (1997),

- archiwalne numery paryskiej jidyszowej gazety „Undzer Wort” i „Undzer Weg" $(1999)^{17}$.

\section{Nowe wyzwania}

Rok 2002 wyznaczył kolejną zmianę w historii biblioteki, która wspólnie z AEDCY przekształciła się w Maison de la Culture Yiddish-Bibliothèque Medem. Jeszcze raz zmieniła się siedziba biblioteki. Najpierw zajmowała lokal przy 18 passage Saint-Pierre Amelot, następnie 29, Rue du Chateaud'Eau dokąd przeniosła się w 2009 roku. Cel, jaki przyświeca bibliotece i jej

\footnotetext{
${ }^{16}$ Ogromną rolę w popularyzacji studiów nad językiem żydowskim odegrał Icchok Niborski. Kiedy w 1979 r. przybył do Paryża miał pierwotnie pozostać tylko trzy miesiące. Zachęcony przez grupe jidyszystów do pozostania i kontynuowania pracy pozostał w Paryżu do dziś. Był inicjatorem licznych przedsięwzięć propagujących jidysz. Dzięki niemu biblioteka Medem stała się jednym z najważniejszych ośrodków badań nad kulturą żydowską w Europie.

${ }^{17}$ Rozier G.: dz. cyt., s. 29.
} 
pracownikom to służenie kulturze jidysz realizowany poprzez wielokrotnie organizowane w ciagu roku programy i kursy, które mają przybliżyć mieszkańcom Paryża oraz sympatykom biblioteki kulturę żydowską.

\section{Il. 2. Czytelnia biblioteki Medem.}

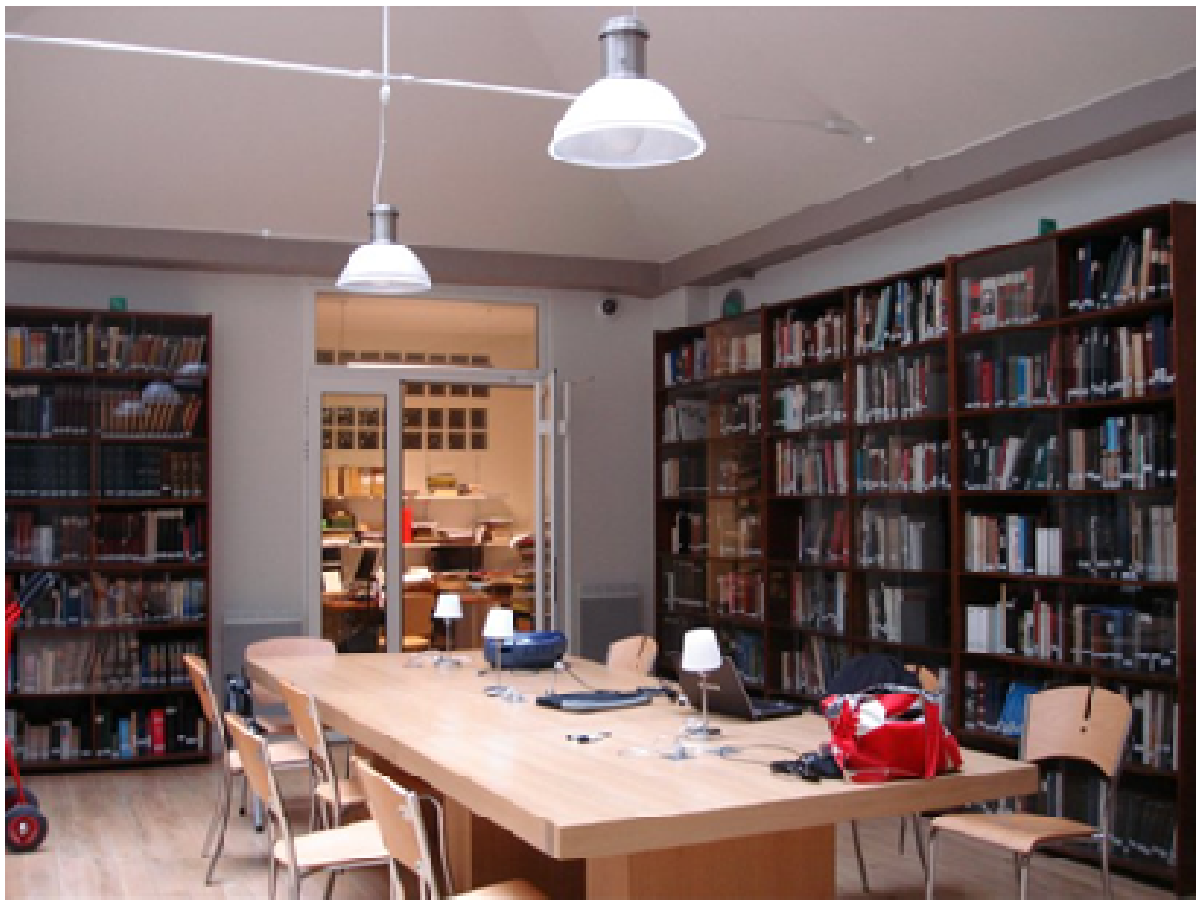

Źródło: http://yiddishweb.com/Locaux/Locauxeng.html.

\section{Zbiory biblioteki}

Zrąb główny księgozbioru stanowi:

- ok. 30 tys. książek, z czego 21 tys. to książki w jidysz, pozostałe 10 tys. to książki dotyczące tematyki żydowskiej wydane w językach łacińskich np. francuskim, polskim, angielskim, niemieckim; biblioteka dysponuje bardzo dużą liczbą dubletów, które pochodzą bądź z prywatnych kolekcji, bądź z innych bibliotek; ogółem liczba nieskatalogowanych dubletów wynosi ok. 30 tys.,

- 1 tys. tytułów czasopism, z czego 200 tytułów stanowi zamkniętą całość; pozostałe czasopisma są w miarę możliwości i dostępności uzupełniane oraz systematycznie katalogowane, 
- gazety dzienne, w tym wszystkie numery warszawskiej gazety „Hajnt” i „Der Moment” zostały zmikrofilmowane; komplet paryskich gazet jak „Undzer sztime” (kompletny w 70\%), „Arbter-Wort”, „Undzer Weg”, „Undzer Wort” (kompletny w 70\%), „Naje Prese” (kompletny tylko w 20\%),

- zbiory audiowizualne (ogółem 7,5 tys. jednostek): kasety z nagraniami piosenek, pieśni religijnych, wykłady w jidysz; filmy (ok. 150 tytułów); w ostatnich latach wszystkie nagrania poddano digitalizacji i zostały włączane do katalogu on-line,

- archiwa 15 pisarzy żydowskich, którzy w większości żyli i tworzyli we Francji np. Mosze Waldman, Riwka Kope, Elchon Wogler oraz Alter Kacyzne i Mosze Broderson - te wyjątkowe zbiory zostały przekazane bibliotece po śmierci pisarzy przez członków ich rodzin,

- 300 plakatów w jidysz oraz w języku francuskim o różnej tematyce,

- cimelia, do których zalicza się kilka wydań starej literatury jidysz, książki wydawane przez modernistów żydowskich, zawierających ilustracje Pereca Markisza, Der Nistera, Dawida Hofsztejna, Henryka Berlewiego, El Lisickiego.

Wobec rosnącego zainteresowania zbiorami, dotychczasowy katalog kartkowy przestał być wystarczający i satysfakcjonujący, zważywszy, że do biblioteki w celu przeprowadzenia kwerendy przyjeżdżały osoby z niemal całego świata. W 2000 r. biblioteka przystapiła do tworzenia katalogu komputerowego Rachel. Do opracowywania zbiorów wybrano program ALEPH 300, który pozwala na jednoczesne wprowadzanie opisów bibliograficznych w języku łacińskim i w jidysz. Już w 2004 r. biblioteka Medem wspólnie z bibliotekami Alliance Israélite Universelle i Séminaire Israélite de France połączyły swoje katalogi i utworzyły wspólną Europejską Sieć Judaiców i Hebraiców w Bibliotekach (Réseau Européen des Bibliothèques Judaica et Hebraica) dostępną online pod adresem http://www.rachelnet.net. W kolejnych latach do sieci dołączyły jeszcze cztery biblioteki.

W chwili obecnej katalog Rachel stanowi największą bazę bibliograficzną rejestrującą literaturę szeroko rozumianej tematyki żydowskiej ${ }^{18}$. Katalog oferuje wyszukiwanie proste i zaawansowane. Jednocześnie w czasie przeglądania katalogu czytelnik może wybrać bibliotekę, której zasoby chce przejrzeć. Ogromną zaletą wspólnego katalogu jest przede wszystkim oszczędność czasu. Na szczególną uwagę zasługują rekordy wprowadzane w języku jidysz. Można je wyszukiwać na kilka sposobów:

- stosując zapis transliteracji przyjęty przez Instytut YIVO np. Asz Szolem Ash Sholem,

${ }^{18}$ W 2009 r. katalog Rachel obejmował 200000 rekordów. Zob. Rozier G.: dz. cyt., s. 33 . 
- $\quad$ wpisując w pole tytułu/hasła/nazwiska frazę w języku oryginału np. po wpisaniu w pole wyszukiwania nazwiska Kacenelson Icchak (wersja polska nazwiska), wyświetlą nam się następujące wersje: Katzenelson Yitskhok, Kacenelson, Yishaq, Kacenelson, Icchok, Katsenelson, Yitskhok, Katzenelson, Yitzhaq, Katzenelson, Itzhak, Katzenelson, Jizchak, Katzenelson, Jitzchak, Katzenelson, Yitzhak.

- $\quad$ wpisując w pole tytułu/hasła/nazwiska frazę w języku jidysz.

Biblioteka Medem jest otwarta dla wszystkich czytelników chcących zgłębiać kulturę, historią czy literaturę żydowską. Pomimo tego, że gromadzi zbiory o tematyce żydowskiej, jest instytucją świecką. Jest czynna codziennie, z wyjątkiem świąt żydowskich i niedziel.

Większość zbiorów udostępnianych jest bezpłatnie na miejscu, w czytelni, w godzinach pracy biblioteki. Największe uprawnienia mają członkowie należący do stowarzyszenia Maison de la Culture Yiddish. W przeciwieństwie do pozostałych czytelników mogą wypożyczać książki bezpłatnie, natomiast osoby spoza stowarzyszenia zobowiązane są do uiszczenia kaucji w wysokości 23 euro za każdy wypożyczony wolumin i mogą wypożyczać 3 książki na okres jednego miesiąca. Biblioteka pobiera także opłaty za korzystanie z zasobów w wysokości 3 euro miesięcznie bądź roczną opłatę w wysokości 30 euro.

Biblioteka boryka się przede wszystkim z brakiem wystarczających funduszy na zakup książek, a także z niewystarczającą liczbą etatowych bibliotekarzy. W chwili obecnej na stanowiskach bibliotekarskich zatrudnione są dwie bibliotekarki-jidyszystki. Znajomości jidysz nie jest bez znaczenia. W tym właśnie języku najczęściej realizowane są zapytania czytelników.

\section{Działalność popularyzacyjna}

Maison de la Culture Yiddish od ponad 12 lat oferuje czytelnikom szereg zajęć przybliżających zarówno kulturę żydowską jak i język jidysz. Lekcje jidysz prowadzone są na kilku poziomach zaawansowania, z których ogółem korzysta 160 uczestników. Naturalnym następstwem znajomości języka jest sięganie po książki pisane w oryginale. Innowacją (niewiele instytucji je prowadzi) są lekcje dla dzieci od 3 do 12 roku życia, które uczą się języka swoich dziadków, a przy okazji poznają bogactwo swojej kultury. Ogromną popularnością cieszą się seminaria literackie organizowane raz w miesiącu, na które słuchacze przyjeżdżają z całego świata. Językiem wykładowym tych seminariów jest jidysz, co daje niebywałą okazję do pogłębiania wiedzy z zakresu literatury, możliwość wymiany poglądów, myśli z naukowcami i badaczami literatury, a także najzwyczajniej okazję do porozmawiania w jidysz. 
Miłośnicy jidysz mają możliwość nauki, dyskusji w tym języku każdego roku podczas wakacyjnego kursu jidysz. Wysoki poziom zajęć przyciaga studentów, doktorantów, osoby starsze z całego świata. Przez trzy tygodnie jedynym językiem, który rozbrzmiewa w gmachu Maison de la Culture Yiddish jest właśnie język żydowski.

Oprócz kursów - Maison de la Culture Yiddish wydaje własny dwujęzyczny biuletyn, w którym informuje o nowościach oraz bieżących wydarzeniach. Jednak tym, co zasługuje na specjalną uwagę są wydawnictwa Bibliothèque Medem, ukazujące się od 1997 roku. Do tej pory opublikowano m.in. słowniki językowe, z których korzystają studenci na całym świecie (słownik jidysz-francuski, słownik hebraizmów), podręczniki dla dzieci do nauki języka, dwujęzyczne edycje poezji, a także liczne przekłady literatury z jidysz na język francuski. Od 2008 r. wydawane jest czasopismo literackie w jidysz Gilgulim pod redakcją Gilles Rozier, kierownika instytucji, w którym wiele miejsca poświęca się współczesnej literaturze żydowskiej.

\section{Podsumowanie}

Obecnie, po największej katastrofie w dziejach ludzkości, jaką bez wątpienia był Holocaust, biblioteka Medem w Paryżu jest miejscem unikalnym. $\mathrm{Z}$ dużym powodzeniem przekazuje kolejnym pokoleniom dziedzictwo kultury żydowskiej, dbając o ciągły rozwój i powiększanie swojej kolekcji. „Wejście do domu jidysz jest spotkaniem z małym światem jidysz, który dociera do wszystkich grup wiekowych, narodów, wykracza poza przekonania polityczne i różnice religijne. U podstaw wszystkich tych przedsięwzięć jest niekwestionowane przywiązanie do języka jidysz" ${ }^{19}$.

\section{Bibliografia}

1. Beer H.: Yiddish without Yiddish. „European Judaism” 2009, vol. 42, nr 2

2. Niborski I.: Yiddish culture in France and in the French-speaking areas, „European Judaism" 2009, vol. 42, nr 2, p. 3-9

3. Pamięć: historia Żydów polskich przed, w czasie, i po Zagładzie, red. F. Tych, Warszawa: Gołda Tencer : Fundacja Shalom, 2004. - ISBN 83-901016-3-7

4. Polski stownik judaistyczny: dzieje, kultura, religia, ludzie, T. 1. Oprac. Z. Borzymińska, R. Żebrowski, Warszawa: Prószyński i Ska, 2003. - ISBN 83-7255-126-X

5. Polski stownik judaistyczny: dzieje, kultura, religia, ludzie, T. 2. Oprac. Z. Borzymińska, R. Żebrowski, Warszawa: Prószyński i Ska, 2003. - ISBN 83-7255-175-8

6. Rozier G.: The Bibliothèque Medem: eighty years serving Yiddish culture. „Judaica Librarianship" 2009, vol. 15, s. 25-34

${ }^{19}$ Beer H.: dz. cyt., s. 17. 
7. Szuchta R., Trojański P.: Holocaust: zrozumieć dlaczego, Warszawa: Mówią wieki : Bellona, 2006. - ISBN 83-86156-07-4, 83-11-09775-5

8. Weinberg D.: The reconstruction of the French Jewish community after world war II, [W:] She'erit hapletah, 1944-1948: rehabilitation and political struggle: proceedings of the sixth Yad Vashem International Historical Conference, Jerusalem 1985. Dostępny w Internecie: http://www.lekket.com/ data/articles/008-000010_000.pdf [data dostępu: 28 sierpnia 2012] 